\title{
ANALISA OUTAGE COST PADA OPERASI KERETA REL LISTRIK PT KAI COMMUTER JABODETABEK TAHUN 2015
}

\author{
Agung Tryono Muhamad*), Tejo Sukmadi dan Bambang Winardi \\ Departemen Teknik Elektro, Universitas Diponegoro \\ Jl. Prof. Sudharto, SH, Kampus UNDIP Tembalang, Semarang 50275, Indonesia \\ ${ }^{*}$ E-mail: agungtryono@ rocketmail.com
}

\begin{abstract}
Abstrak
Transportasi sudah menjadi kebutuhan primer untuk manusia. Moda transportasi diharuskan untuk cepat, tepat waktu, selalu tersedia dan menjangkau manapun agar manusia dapat memenuhi kebutuhan tersebut untuk tujuannya. Salah satunya adalah kereta rel listrik (KRL). Berbeda dengan kereta api, kereta ini membutuhkan daya listrik sebagai sumber tenaga penggeraknya. Agar tetap tersedia, moda transportasi ini membutuhkan keandalan yang baik dari sisi pembangkitannya maupun penyalurannya. Namun, masih ditemui adanya outage yang menyebabkan operasi kereta rel listrik ini terganggu. Outage adalah kondisi dimana suatu peralatan atau sistem tidak dapat bekerja sesuai dengan tujuannya karena adanya masalah yang berhubungan dengan peralatan atau sistem tersebut. Hal ini tentunya akan merugikan pihak yang menyediakan jasa transportasi tersebut, dalam hal ini PT KAI Commuter Jabodetabek. Hal ini akan berdampak terhadap berkurangnya kepercayaan masyarakat untuk menggunakan moda transportasi ini, yang tentunya akan mengurangi laba yang diterima oleh PT KAI Commuter Jabodetabek sebagai pihak penyedia jasa transportasi. Dalam penulisan penelitian ini, akan dibahas dampak kerugian secara langsung yang dialami oleh PT KAI Commuter Jabodetabek akibat adanya outage yang dinamakan outage cost. Outage cost dapat dihitung dengan mencari selisih antara pemasukan yang seharusnya diperoleh terhadap biaya operasional yang tidak jadi dikeluarkan akibat terjadinya outage.
\end{abstract}

Kata kunci : transportasi, kereta rel listrik, outage

\begin{abstract}
Transportation has become a primary need nowadays. A fast, punctual, available and long-ranged transportation mode is needed to fulfill our human need to grab our own purpose. One of the transportation mode is kereta rel listrik (KRL). This transportation mode needs electrical power as its main source of power to run. Thus, the availabilty of this transportation mode is very dependent to its efficiency of the power generator and distribution line. The fact is, there's still a variable that turn this system un-efficient, which is called outage. Outage is a condition when a component or system can not run as its purpose because of the trouble in its component or system itself. Outage can make the operation of kereta rel listrik disrupted. Of course, this scene can cause losses to the PT. KAI Commuter Jabodetabek, as the provider of kereta rel listrik service in Jabodetabek. This outage can cause reduction of public trust about this transportation mode and reducing the sum of company's profit. This research provides the direct losses of outage in the kereta rel listrik operation of Jabodetabek by PT KAI Commuter Jabodetabek.
\end{abstract}

Keywords : Transportation, Kereta Rel Listrik, Outage

\section{Pendahuluan}

Seiring dengan berkembangnya zaman, perkembangan teknologi pun juga makin pesat. Teknologi sendiri memliki hubungan yang erat dengan energi listrik, karena hampir semua teknologi pada zaman yang serba berkembang saat ini menggunakan energi listrik sebagai sumber tenaganya. Tanpa adanya energi listrik, kita manusia pasti akan mengalami kesukaran dalam melakukan kegiatan untuk mencapai suatu tujuan, Perkembangan teknologi ini merambah hampir segala aspek dalam kehidupan manusia, seolah kehidupan manusia dimudahkan dengan adanya teknologi ini. Sehingga dapat dikatakan bahwa energi listrik sudah menjadi kebutuhan primer kita sebagai manusia. Salah satu contoh dari perkembangan teknologi yang membutuhkan energi listrik sebagai sumber tenaganya yang memudahkan kehidupan manusia adalah adanya kereta rel listrik (KRL) dalam bidang transportasi.

Adanya moda transportasi kereta rel listrik ini sangat membantu banyak orang, khususnya masyarakat yang berdomisili pada Jakarta, Bogor, Depok, Tangerang dan Bekasi, dimana pada wilayah ini transportasi yang menggunakan jalan raya sudah sangat tidak memungkinkan (macet). Sehingga tidak heran jika moda 
transportasi ini menjadi andalan masyarakat Jabodetabek. Hal ini dibuktikan dengan data yang menunjukkan bahwa terjadi peningkatan jumlah penumpang KRL yang signifikan dari tahun ketahun. Pada tahun 2014, jumlah penumang KRL berada pada angka 560.650 penumpang per hari. Kemudian pada tahun 2015, jumlah penumpang KRL berada pada angka 705.562 penumpang per hari. [1]

Peningkatan jumlah pelanggan PT KAI Commuter Jabodetabek ini tentu harus diimbangi oleh ketersediaan armada dari kereta rel listrik. Makin banyak armada yang ada, maka makin banyak pula kebutuhan daya listrik yang dipelukan untuk pengoperasian kereta api listrik. Oleh karena itu, PT PLN (Persero) sebagai penyedia utama daya listrik bagi kereta rel listrik PT KAI Commuter Jabodetabek harus dapat menyediakan energi listrik dengan keandalan yang tinggi dan PT KAI Commuter Jabodetabek sebagai penyedia jasa transportasi Kereta Rel Listrik harus dapat menyediakan servis Kereta Rel Listrik yang andal agar operasi KRL di Jabodetabek ini dapat berjalan dengan maksimal. Namun pada praktiknya, masih sering dijumpai adanya outage pada operasi KRL Jabodetabek. Adanya outage ini tentunya mengurangi nilai keandalan sistem KRL Jabodetabek.

Pada penelitian sebelumnya, yang telah terdapat penggunaan metode hybrid dalam outage cost, metode case study, metode Customer Survey Method, dan analisa kapasitas daya gardu listrik. Serta untuk jenis dan tipe power outage itu sendiri.

Dalam penelitian “Analisis Outage Cost pada Operasi Kereta Rel Listrik PT KAI Commuter Jabodetabek Tahun 2015" ini disusun untuk mengetahui dampak langsung berupa estimasi nilai ekonomis yang ditimbulkan oleh adanya outage pada pengoperasian kereta api listrik di Jabodetabek. Analisis ini diharapkan dapat memberikan masukan kepada PT KAI Commuter Jabodetabek selaku operator dari kereta rel listrik tersebut.

\section{Metode Penelitian}

\subsection{Outage}

Outage didefinisikan sebagai kondisi dimana suatu peralatan atau sistem tidak dapat bekerja sesuai dengan tujuannya karena adanya masalah yang berhubungan dengan peralatan atau sistem tersebut[2]. Outage ini bisa atau tidak menyebabkan interupsi/interruption dalam servis yang diberikan untuk pelanggan, tergantung konfigurasi sistemnya. Interupsi/interruption adalah hilangnya servis yang diberikan untuk satu pelanggan atau lebih yang disebabkan oleh outage dari peralatan atau sistem, tergantung konfigurasi sistemnya[2].

Keadaan tidak adanya penyediaan ini bisa disengaja maupun tidak disengaja dengan alasan tertentu. Outage dapat terjadi secara disengaja, contohnya saat mengamankan jaringan listrik akibat adanya gangguan petir misalnya. Jika listrik tetap dialirkan saat adanya gangguan petir maka akan membahayakan keadaan sekitar. Outage juga dapat terjadi secara tidak sengaja dengan alasan tertentu, seperti saat adanya gangguan. Faktorfaktor yang menyebabkan terjadinya gangguan tersebut dapat berasal dari luar maupun dalam instalasi sendiri. Gangguan dari luar disebabkan oleh biasanya petir, burung, atau debu sedangkan dari dalam instalasi terutama disebabkan sifat ketahanan yang berubah maupun umur peralatan yang sudah tua.

\subsection{Outage Cost}

Adanya outage, khususnya pada operasi KRL Jabodetabek, menyebabkan kerugian baik pada PT KAI Commuter Jabodetabek maupun pada pelanggan KRL Jabodetabek. Kerugian tersebut dapat dibagi menjadi dua, yaitu kerugian langsung dan tidak langsung. Kerugian tidak langsung berupa hilangnya kepercayaan pelanggan maupun berkurangnya nilai kenyamanan pelanggan terhadap jasa transportasi KRL Jabodetabek. Sedangkan kerugian langsung dapat berupa penggantian alat yang rusak akibat pemadaman yang terjadi secara mendadak maupun hilangnya potensi pemasukan yang dapat diperoleh PT KAI Commuter Jabodetabek saat daya tersambung. Hilangnya potensi pemasukan yang dapat diperoleh PT KAI Commuter Jabodetabek saat daya tersambung dapat dikatakan sebagai outage cost. Outage cost adalah dampak langsung berupa kerugian finansial yang dialami oleh pelanggan listrik akibat adanya interupsi akibat adanya outage.

Penaksiran dampak langsung akan lebih mudah dibandingkan dampak tidak langsung, karena bersifat objektif serta memerlukan usaha yang lebih ringan dan waktu yang lebih singkat. Penaksiran nilai ekonomi dari dampak tidak langsung memerlukan skala yang besar dan studi kasus yang lebih rumit, dimana hal ini tidak menjadi tujuan dari penelitian ini yang bertujuan untuk menyajikan data yang tidak bertele-tele dan user-friendly dengan usaha seminimal mungkin. Sehingga itulah mengapa penelitian ini hanya berfokus untuk membahas estimasi nilai ekonomi dari dampak langsung yang ditimbulkan oleh outage.

Ada beberapa metodologi yang dapat digunakan dalam penaksiran outage cost, antara lain : [3]

1. Case study

2. Indirect analytical method.

3. Customer survey method

\subsection{Indirect Analytical Method}

Dipilihnya metoda ini adalah karena tujuan dari metoda ini untuk mendapatkan pendekatan dengan data yang ada secara umum sehingga mudah didapat tapi tetap bersifat obyektif. Untuk mendapatkan nilai outage cost menggunakan metoda ini, dibutuhkan data berupa tarif tenaga listrik, Gross Domestic Product (GDP) yang 
dibandingkan dengan konsumsi energi listrik [4]. Gross Domestic Product (GDP) adalah suatu nilai dari barang maupun jasa yang diproduksi dalam suatu area geografis dalam suatu interval waktu (biasanya pertahun) [5]. Jadi, metoda ini biasanya digunakan untuk memberikan ide seberapa besar dampak kerugian ekonomi yang disebabkan oleh outage ini.

\subsection{Tarif Tenaga Listrik}

Tarif tenaga listrik merupakan besaran biaya yang harus dibayarkan oleh pelanggan listrik kepada perusahaan penyedia listrik, dalam hal ini PLN, sesuai dengan aturan yang berlaku yang ditetapkan oleh pemerintah. Tarif tenaga listrik di Indonesia dibagi menjadi beberapa kelompok, sesuai dengan tujuan penggunaan energi listrik serta besaran daya listrik yang dipakai. Penggolongan konsumen listrik pada tahun 2015 telah diatur oleh peraturan menteri ESDM no 31 Tahun 2014. Untuk menyediakan suplai listrik yang cukup untuk pengoperasian KRL tiap harinya, PT KAI Commuter Jabodetabek sebagai operator KRL di Jabodetabek mengadakan kontrak dengan PT. PLN. PT KAI Commuter Jabodetabek ditetapkan sebagai pelanggan listrik golongan T/TM, yaitu pelanggan yang membeli listrik untuk keperluan traksi dengan suplai dari PT. PLN adalah tegangan menengah.

Rumusan pembiayaan yang harus dibayarkan oleh PT KAI Commuter Jabodetabek kepada PT. PLN adalah sebagai berikut: [6]

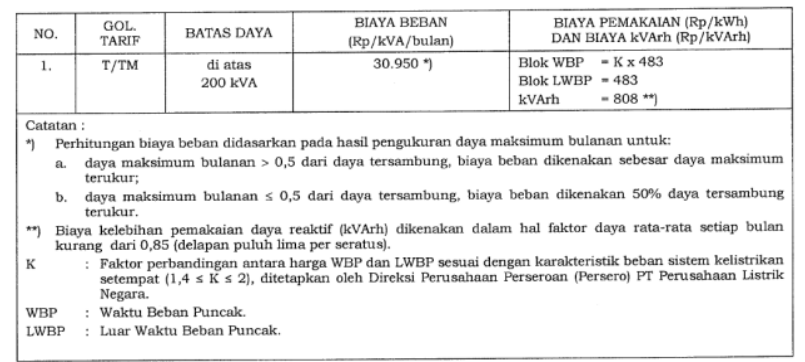

\section{Gambar 1. Pelanggan Listrik Golongan T/TM}

Dari tabel diatas, jumlah biaya listrik yang harus dibayar oleh PT. KAI Commuter Jabodetabek kepada PT. PLN dapat ditentukan. Perhitungan tersebut didasarkan pada daya yang masuk pada gardu traksi. Jadi, jumlah biaya yang harus dibayarkan PT KAI Commuter Jabodetabek adalah sesuai dengan energi listrik yang masuk pada gardu traksinya. Gardu traksi itu sendiri hanya digunakan untuk menyuplai energi yang dibutuhkan oleh operasional KRL.

Jika jumlah biaya listrik yang harus dibayar serta jumlah konsumsi $\mathrm{kWh}$ telah diketahui, maka tarif listrik per $\mathrm{kWh}$ rata-rata dapat diketahui dengan membagi jumlah biaya listrik terhadap jumlah pemakaian $\mathrm{kWh}$. Adapun pada tahun 2015, tarif listrik per kwh rata-rata untuk pelanggan listrik golongan traksi adalah sebesar Rp 483. [6]

\section{Hasil dan Analisa}

Dari penelitian yang telah dilakukan, didapatkan hasil dan analisa dari penelitian sebagai berikut:

\subsection{Jarak Tempuh Operasi KRL Jabodetabek Tahun 2015}

Berdasarkan data rute perjalanan dan Gapeka (Grafik Perjalanan Kereta Api) KRL PT. KAI Commuter Jabodetabek pada tahun 2015, didapatkan data perhitungan total jarak tempuh KRL per harinya sebagai berikut:

Tabel 1. Hasil Perhitungan Total Jarak Tempuh per Hari Operasi KRL Jabodetabek Tahun 2015

\begin{tabular}{|c|c|c|c|}
\hline Rute Perjalanan & $\begin{array}{l}\text { Total } \\
\text { Perjalanan per } \\
\text { Hari } \\
\end{array}$ & Jarak (Km) & $\begin{array}{l}\text { Total Jarak } \\
\text { Tempuh per } \\
\text { Hari }(\mathrm{Km})\end{array}$ \\
\hline $\begin{array}{l}\text { Bogor - Depok - } \\
\text { Manggarai (PP) }\end{array}$ & 11 & 44,924 & 494,164 \\
\hline Bogor - Depok (PP) & 32 & 22,13 & 708,16 \\
\hline Bogor - Depok - & & & \\
\hline $\begin{array}{l}\text { Manggarai } \\
\text { Jatinegara (PP) }\end{array}$ & 88 & 47,576 & $4.186,688$ \\
\hline Bogor - Depok - & & & \\
\hline $\begin{array}{l}\text { Manggarai - Jakarta } \\
\text { Kota (PP) }\end{array}$ & 131 & 54,812 & $7.180,372$ \\
\hline $\begin{array}{l}\text { Bogor - Depok - } \\
\text { Manggarai - Duri (PP) }\end{array}$ & 55 & 54,582 & $3.002,01$ \\
\hline Manggarai - Duri (PP) & 32 & 9,658 & 309,056 \\
\hline Nambo - Depok (PP) & 6 & 18,351 & 110,106 \\
\hline $\begin{array}{l}\text { Depok - Manggarai - } \\
\text { Duri (PP) }\end{array}$ & 14 & 32,452 & 454,328 \\
\hline $\begin{array}{l}\text { Depok - Manggarai - } \\
\text { Jakarta Kota (PP) }\end{array}$ & 27 & 32,682 & 915,096 \\
\hline $\begin{array}{l}\text { Depok - Manggarai - } \\
\text { Jatinegara (PP) }\end{array}$ & 7 & 25,446 & 178,122 \\
\hline $\begin{array}{l}\text { Nambo - Depok - } \\
\text { Manggarai - Duri (PP) }\end{array}$ & 4 & 50,803 & 203,212 \\
\hline $\begin{array}{l}\text { Manggarai - Tanah } \\
\text { Abang }\end{array}$ & 2 & 6,026 & 12,052 \\
\hline $\begin{array}{l}\text { Manggarai - Kampung } \\
\text { Bendan }\end{array}$ & 1 & 11,252 & 11,252 \\
\hline Bojong gede - Depok & 1 & 14,612 & 14,612 \\
\hline $\begin{array}{l}\text { Manggarai - Jakarta } \\
\text { Kota }\end{array}$ & 1 & 9,888 & 9,888 \\
\hline Jakarta Kota & & & \\
\hline $\begin{array}{l}\text { Kampung Bendan - } \\
\text { Tanjung Priok (PP) }\end{array}$ & 12 & 11,642 & 139,704 \\
\hline Jakarta Kota & & & \\
\hline $\begin{array}{l}\text { Kampung Bendan } \\
\text { (PP) }\end{array}$ & 52 & 1,364 & 70,928 \\
\hline Duri - Tangerang (PP) & 92 & 19,297 & $1.775,324$ \\
\hline $\begin{array}{l}\text { Parung Panjang - Maja } \\
\text { (PP) }\end{array}$ & 5 & 21,081 & 105,405 \\
\hline Tanah Abang - & & & \\
\hline $\begin{array}{l}\text { Serpong - Parung } \\
\text { Panjang (PP) }\end{array}$ & 67 & 34,546 & $2.314,582$ \\
\hline Tanah Abang & & & \\
\hline $\begin{array}{l}\text { Serpong - Parung } \\
\text { Panjang - Maja (PP) }\end{array}$ & 36 & 55,627 & $2.002,572$ \\
\hline $\begin{array}{l}\text { Tanah Abang } \\
\text { Serpong (PP) }\end{array}$ & 38 & 24,278 & 922,564 \\
\hline
\end{tabular}


Tabel 1. (lanjutan)

\begin{tabular}{|c|c|c|c|}
\hline Rute Perjalanan & $\begin{array}{l}\text { Total } \\
\text { Perjalanan per } \\
\text { Hari }\end{array}$ & Jarak (Km) & $\begin{array}{l}\text { Total Jarak } \\
\text { Tempuh per } \\
\text { Hari }(\mathrm{Km})\end{array}$ \\
\hline $\begin{array}{l}\text { Manggarai - Bekasi } \\
\text { (PP) }\end{array}$ & 28 & 17,454 & 488,712 \\
\hline Jakarta & & & \\
\hline $\begin{array}{l}\text { Manggarai - Bekasi } \\
\text { (PP) }\end{array}$ & 128 & 27,342 & $3.499,776$ \\
\hline
\end{tabular}

Dari tabel diatas dapat dilihat bahwa operasi KRL di Jabodetabek pada tahun 2015 menempuh rata-rata jarak 29.108,69 Km dalam 870 perjalanan di tiap-tiap rute setiap harinya. Rute perjalanan terpanjang di operasi KRL Jabodetabek adalah rute Tanah Abang - Serpong - Parung Panjang - Maja (PP) sebesar 55,627 Km, lalu rute perjalanan terpendek di operasi KRL Jabodetabek adalah rute Jakarta Kota - Kampung Bendan (PP) sebesar 1,364 Km. Rute perjalanan paling ramai digunakan oleh masyarakat pada operasi KRL Jabodetabek adalah rute Bogor - Depok - Manggarai - Jakarta Kota (PP) sebesar 131 perjalanan tiap harinya, lalu rute perjalanan paling sepi digunakan oleh masyarakat pada operasi KRL Jabodetabek adalah rute Depok - Jakarta Kota, Manggarai - Kampung Bendan, Bojong gede - Depok, dan Manggarai - Jakarta Kota sebesar 1 perjalanan tiap rute setiap harinya. Kemudian, rute perjalanan dengan jarak tempuh paling jauh di operasi KRL Jabodetabek adalah rute Bogor Depok - Manggarai - Jakarta Kota (PP) dengan jarak tempuh sebesar 7.180,372 Km tiap harinya. Dan rute perjalanan dengan jarak tempuh paling dekat di operasi KRL Jabodetabek adalah rute Manggarai - Jakarta Kota dengan jarak tempuh sebesar 9,888 Km tiap harinya

\subsection{Konsumsi Energi Listrik Operasi KRL Jabodetabek Tahun 2015}

Energi listrik yang digunakan PT. KAI Commuter Jabodetabek untuk mengoperasikan KRL berasal dari pihak PT. PLN (Persero) sebagai penyedia listrik negara. Oleh karena itu, PT. KAI Commuter Jabodetabek dalam mengoperasikan KRL dikategorikan sebagai pelanggan listrik golongan traksi. Penggolongan tersebut sesuai dengan permen ESDM nomor 31 tahun 2012, yaitu pelanggan yang menggunakan listrik untuk keperluan traksi digolongkan menjadi pelanggan listrik golongan traksi.

Nilai konsumsi energi (kWh) operasi KRL Jabodetabek oleh PT KAI Commuter Jabodetabek tahun 2015 dapat dihitung.dengan cara sebagai berikut: [7]

$$
S E C=\frac{S E O}{\mu}
$$

Dengan,

$$
\begin{aligned}
S E O & =\text { Total Energy output of driving axle } \\
& =E a+E g+E f
\end{aligned}
$$

$$
\begin{gathered}
=\left(\frac{0,01072 V m^{2}}{D} \times \frac{W e}{W}\right) \pm 2,725 W G D^{\prime} \\
+0,02778 \times \gamma \times \frac{D^{\prime}}{D}
\end{gathered}
$$

Keterangan :

SEC = Specific Energy Consumption KRL (Wh/tonne.km)

SEO = Specific Energy Output KRL (Wh/tonne.km)

$\mu \quad=$ Efisiensi gear transmisi dan motor KRL

$\mathrm{Ea} \quad=$ Energi pada driving axle untuk mempercepat KRL

Eg = Energi pada driving axle untuk menanggulangi Gradien

Ef = Energi pada driving axle untuk menanggulangi Friksi

$\mathrm{Vm} \quad=$ Kecepatan maksimal KRL $(\mathrm{Km} / \mathrm{h})$

$\mathrm{D}=$ Jarak antar stasiun $(\mathrm{Km})$

D' = Jarak Pengereman KRL $(\mathrm{Km})$

$\mathrm{We} \quad=$ Berat efektif KRL (Ton)

$\mathrm{W} \quad=$ Berat mati (Dead Weight) KRL (Ton)

$\mathrm{G} \quad=$ Gradien $(\%)$

$\gamma \quad=$ Resistansi pada KRL

Dari persamaan diatas dapat dihitung Specific Energy Consumption (SEC) antar stasiun KRL Jabodetabek sebagai berikut, dengan asumsi seluruh perjalanan KRL Jabodetabek menempuh rute datar (gradien 0\%), efisiensi gear transmisi dan motor KRL Jabodetabek sebesar 80 persen dan dengan resistansi pada KRL sebesar $50 \mathrm{~N} / \mathrm{Kg}$.

Dengan diketahuinya nilai Specific Energy Consumption (SEC) antar stasiun KRL Jabodetabek, maka nilai konsumsi energi per perjalanan serta biaya listrik per perjalanan operasi KRL Jabodetabek tahun 2015 pun dapat diketahui melalui persamaan sebagai berikut:

$$
\begin{aligned}
E n(\operatorname{trip}) & =S E C \times w \times d \\
& =S E C \times 435 \text { Tonne } \times d \\
E C(\operatorname{trip}) & =E n(\operatorname{trip}) \times E \\
& =E n(\text { trip }) \times R p 483 / \mathrm{kWh}
\end{aligned}
$$

Keterangan :

$\mathrm{En}_{\text {(trip) }}=$ Konsumsi Energi KRL per perjalanan (Wh)

SEC = Specific Energy Consumption (Wh/Tonne. Km)

$\mathrm{d}=$ Jarak yang ditempuh KRL per perjalanan $(\mathrm{Km})$

$\mathrm{w} \quad=$ Berat KRL (Tonne)

$\mathrm{EC}_{(\text {trip) }}=$ Biaya listrik per perjalanan (Rupiah)

ET = Harga per $\mathrm{kWh}$ golongan traksi tahun 2015 (Rupiah)

Dari persamaan-persamaan diatas, didapatkan tabel hasil perhitungan konsumsi energi KRL per perjalanan serta biaya listrik per perjalanan sebagai berikut: 
Tabel 2. Hasil Perhitungan Konsumsi Energi dan Biaya Listrik per Perjalanan Operasi KRL Jabodetabek Tahun 2015

\begin{tabular}{|c|c|c|c|}
\hline Rute Perjalanan & $\begin{array}{l}\text { Jarak } \\
(\mathrm{Km})\end{array}$ & $\begin{array}{l}\text { Konsumsi } \\
\text { Energi per } \\
\text { Perjalanan } \\
\text { (kWh) }\end{array}$ & $\begin{array}{l}\text { Biaya Listrik } \\
\text { per Perjalanan } \\
\text { (Rupiah) }\end{array}$ \\
\hline Bogor - Depok (PP) & 22,13 & 63,983 & 30.904 \\
\hline $\begin{array}{l}\text { Bogor - Depok - } \\
\text { Manggarai (PP) }\end{array}$ & 44,924 & 241,332 & 116.564 \\
\hline $\begin{array}{l}\text { Bogor - Depok - } \\
\text { Manggarai - Jatinegara } \\
\text { (PP) }\end{array}$ & 47,576 & 255,779 & 123.541 \\
\hline $\begin{array}{l}\text { Bogor - Depok - } \\
\text { Manggarai - Jakarta } \\
\text { Kota (PP) }\end{array}$ & 54,812 & 350,183 & 169.139 \\
\hline $\begin{array}{l}\text { Bogor - Depok - } \\
\text { Manggarai - Duri (PP) }\end{array}$ & 54,582 & 302,795 & 146.250 \\
\hline $\begin{array}{l}\text { Manggarai - Duri (PP) } \\
\text { Nambo - Depok (PP) }\end{array}$ & $\begin{array}{c}9,658 \\
18,351\end{array}$ & $\begin{array}{l}61,462 \\
74,733\end{array}$ & $\begin{array}{l}29.686 \\
36.096\end{array}$ \\
\hline $\begin{array}{l}\text { Depok - Manggarai - Duri } \\
\text { (PP) }\end{array}$ & 32,452 & 238,812 & 115.346 \\
\hline $\begin{array}{l}\text { Depok - Manggarai - } \\
\text { Jakarta Kota (PP) }\end{array}$ & 32,682 & 286,2 & 138.235 \\
\hline $\begin{array}{l}\text { Depok - Manggarai - } \\
\text { Jatinegara (PP) }\end{array}$ & 25,446 & 191,796 & 92.637 \\
\hline $\begin{array}{l}\text { Nambo - Depok - } \\
\text { Manggarai - Duri (PP) }\end{array}$ & 50,803 & 313,545 & 151.442 \\
\hline $\begin{array}{l}\text { Manggarai - Tanah } \\
\text { Abang }\end{array}$ & 6,026 & 46,624 & 22.519 \\
\hline $\begin{array}{l}\text { Manggarai - Kampung } \\
\text { Bendan }\end{array}$ & 11,252 & 123,78 & 59.786 \\
\hline Bojong gede - Depok & 14,612 & 31,436 & 15.184 \\
\hline $\begin{array}{l}\text { Manggarai - Jakarta } \\
\text { Kota } \\
\text { Jakarta Kota - Kampung }\end{array}$ & 9,888 & 108,851 & 52.575 \\
\hline $\begin{array}{l}\text { Bendan - Tanjung Priok } \\
\text { (PP) }\end{array}$ & 11,642 & 59,466 & 28.722 \\
\hline $\begin{array}{l}\text { Jakarta Kota - Kampung } \\
\text { Bendan (PP) }\end{array}$ & 1,364 & 14,292 & 7.211 \\
\hline Duri - Tangerang (PP) & 19,297 & 145,844 & 70.443 \\
\hline $\begin{array}{l}\text { Parung Panjang - Maja } \\
\text { (PP) }\end{array}$ & 21,081 & 106,119 & 51.256 \\
\hline $\begin{array}{l}\text { Tanah Abang - Serpong - } \\
\text { Parung Panjang (PP) } \\
\text { Tanah Abang - Serpong - }\end{array}$ & 34,546 & 149,681 & 72.296 \\
\hline $\begin{array}{l}\text { Parung Panjang - Maja } \\
\text { (PP) }\end{array}$ & 55,627 & 239,543 & 115.699 \\
\hline $\begin{array}{l}\text { Tanah Abang - Serpong } \\
\text { (PP) }\end{array}$ & 24,278 & 104,518 & 50.482 \\
\hline Manggarai - Bekasi (PP) & 17,454 & 102,712 & 49.610 \\
\hline $\begin{array}{l}\text { Jakarta Kota } \\
\text { Manggarai - Bekasi (PP) }\end{array}$ & 27,342 & 211,562 & 102.185 \\
\hline
\end{tabular}

Dari tabel dan grafik-grafik diatas dapat dilihat bahwa rute perjalanan KRL yang membutuhkan energi listrik terbanyak adalah rute Bogor - Depok - Manggarai - Jakarta Kota (PP) dengan nilai 350,183 $\mathrm{kWh}$ per perjalanannya, dan rute perjalanan KRL yang membutuhkan energi listrik paling sedikit adalah rute Jakarta Kota - Kampung Bendan (PP) dengan nilai 14,292 kWh per perjalanan tiap harinya. Kemudian, rute perjalanan KRL yang membutuhkan biaya listrik termahal adalah rute Bogor - Depok - Manggarai Jakarta Kota (PP) dengan harga Rp 169.139 per perjalanannya, dan rute perjalanan KRL yang membutuhkan biaya listrik termurah adalah rute Jakarta
Kota - Kampung Bendan (PP) dengan harga Rp 7.211 per perjalanan tiap harinya.

\subsection{Pemasukan yang Diperoleh Tiap Perjalanan}

Nilai pemasukan yang dapat diperoleh PT. KAI Commuter Jabodetabek dapat diketahui dengan menggunakan persamaan sebagai berikut:

$$
\operatorname{Re}(\operatorname{trip})=\frac{E C(\text { trip })}{R}
$$

Keterangan :

$$
\begin{array}{ll}
\mathrm{Re}_{\text {(trip) }} & =\text { Pemasukan tiap perjalanan (Rupiah) } \\
\mathrm{EC}_{\text {(trip) }} & =\text { Biaya listrik per perjalanan (Rupiah) } \\
\mathrm{R} & =\text { Rasio }
\end{array}
$$

Yang dimaksud oleh rasio disini adalah proporsi antara biaya listrik per tahun $\left(\mathrm{EC}_{(\mathrm{y})}\right)$ terhadap pemasukan yang diperoleh pertahun $\left(\operatorname{Re}_{(\mathrm{y})}\right)$ untuk mengetahui nilai pemasukan yang seharusnya didapatkan jikalau terjadi pembatalan perjalanan akibat pemadaman listrik. Rasio dapat dirumuskan sebagai berikut :

$$
R=\frac{E C(y)}{\operatorname{Re}(y)}=\frac{R p 148,85 \text { Milyar }}{R p 1.729,746 \text { Milyar }}=0,086
$$

Keterangan :

$\begin{array}{ll}\mathrm{R} & =\text { Rasio } \\ \mathrm{EC}_{(\mathrm{y})} & =\text { Biaya listrik per tahun (Rupiah) [2] } \\ \operatorname{Re}_{(\mathrm{y})} & =\text { Pemasukan tiap per tahun (Rupiah) [2] }\end{array}$

Dari persamaan-persamaan diatas, didapatkan tabel hasil perhitungan pemasukan per pejalanan PT. KAI Commuter Jabodetabek sebagai berikut:

Tabel 3. Hasil Perhitungan Pemasukan per Perjalanan Operasi KRL Jabodetabek Tahun 2015

\begin{tabular}{lcc}
\hline Rute Perjalanan & $\begin{array}{l}\text { Jarak } \\
\text { (Km) }\end{array}$ & $\begin{array}{l}\text { Pemasukan } \\
\text { per Perjalanan } \\
\text { (Rupiah) }\end{array}$ \\
\hline Bogor - Depok (PP) & 22,13 & 359.345 \\
Bogor - Depok - Manggarai (PP) & 44,924 & 1.355 .390 \\
Bogor - Depok - Manggarai - & 47,576 & 1.436 .524 \\
Jatinegara (PP) & & \\
Bogor - Depok - Manggarai - & 54,812 & 1.966 .727 \\
Jakarta Kota (PP) & & \\
Bogor - Depok - Manggarai - Duri & 54,582 & 1.700 .580 \\
(PP) & 9,658 & 345.189 \\
Manggarai - Duri (PP) & 18,351 & 419.722 \\
Nambo - Depok (PP) & 32,452 & 1.341 .234 \\
Depok - Manggarai - Duri (PP) & 32,682 & 1.607 .381 \\
Depok - Manggarai - Jakarta Kota & & 1.077 .179 \\
Depok - Manggarai - Jatinegara & 25,446 & \\
(PP) & & 1.760 .957 \\
Nambo - Depok - Manggarai - Duri & 50,803 & 261.854 \\
(PP) & 11,252 & 695.184 \\
Manggarai - Tanah Abang & 14,612 & 176.554 \\
Manggarai - Kampung Bendan & 9,888 & 611.336 \\
\hline Bojong gede - Depok & 22,13 & \\
Manggarai - Jakarta Kota & & \\
\hline
\end{tabular}


TRANSIENT, VOL. 7, NO. 3, SEPTEMBER 2018, ISSN: 2302-9927, 699

Tabel 3. (lanjutan)

\begin{tabular}{lcc}
\hline Rute Perjalanan & $\begin{array}{l}\text { Jarak } \\
(\mathrm{Km})\end{array}$ & $\begin{array}{l}\text { Pemasukan } \\
\text { per Perjalanan } \\
\text { (Rupiah) }\end{array}$ \\
\hline $\begin{array}{l}\text { Jakarta Kota - Kampung Bendan - } \\
\text { Tanjung Priok (PP) }\end{array}$ & 11,642 & 333.976 \\
Jakarta Kota - Kampung Bendan & 1,364 & 83.848 \\
(PP) & 19,297 & 819.099 \\
Duri - Tangerang (PP) & 21,081 & 595.994 \\
Parung Panjang - Maja (PP) & 34,546 & 840.650 \\
Tanah Abang - Serpong - Parung & & \\
Panjang (PP) & & 1.345 .339 \\
Tanah Abang - Serpong - Parung & 55,627 & 587.002 \\
Panjang - Maja (PP) & 24,278 & 576.858 \\
Tanah Abang - Serpong (PP) & 17,454 & 1.188 .194 \\
Manggarai - Bekasi (PP) & \\
Jakarta Kota - Manggarai - Bekasi & 27,342 & \\
(PP) & & \\
\hline
\end{tabular}

Tabel diatas menunjukkan bahwa semakin panjang jarak tempuh suatu KRL, maka pemasukan per perjalanan $\left(\operatorname{Re}_{\text {(trip) }}\right)$ akan semakin besar. Hal ini sesuai dengan logika yang ada yaitu suatu perusahaan, dimana disini adalah PT. KAI Commuter Jabodetabek sebagai operator KRL, tidak mau mengalami rugi. Dengan makin panjangnya suatu rute yang ditempuh, maka usaha yang harus ditanggung operator KRL untuk operasi rute tersebut pun makin besar. Sehingga, besar pemasukan per perjalanan yang diperoleh harus berbanding lurus dengan besar usaha yang dilakukan dalam operasi KRL, dimana dalam hal ini dinyatakan dalam biaya listrik per perjalanan $\left(\mathrm{EC}_{(\text {trip })}\right)$, yang juga berbanding lurus dengan jarak tempuh KRL.

Rute perjalanan KRL dengan pemasukan terbesar per perjalanan adalah rute Bogor - Depok - Manggarai Jakarta Kota (PP) sebesar Rp 1.966.727, lalu rute perjalanan KRL dengan pemasukan paling sedikit per perjalanan adalah rute Jakarta Kota - Kampung Bendan (PP) sebesar $\mathrm{Rp}$ 83.848. Hal ini dikarenakan kedua rute tersebut merupakan rute terpanjang dan terpendek pada operasi KRL Jabodetabek tahun 2015. Hal ini sudah sesuai dengan teori yang ada, dimana besar pemasukan per perjalanan yang diperoleh harus berbanding lurus dengan besar usaha dimana dalam hal ini dinyatakan dalam biaya listrik per perjalanan $\left(\mathrm{EC}_{(\text {trip })}\right)$, yang juga berbanding lurus dengan jarak tempuh KRL.

\subsection{Outage Cost Operasi KRL Jabodetabek Tahun 2015}

Perhitungan outage cost dilakukan dengan cara mencari selisih antara pemasukan yang diperoleh per perjalanan $\left(\operatorname{Re}_{\text {(trip) }}\right)$ dengan biaya listrik per perjalanan tersebut $\left(\mathrm{EC}_{(\text {(trip) }}\right)$. [8] Perhitungan diatas dapat dituangkan menjadi persamaan sebagai berikut :

$$
O C(\text { trip })=\operatorname{Re}(\text { trip })-E C(\text { trip })
$$

Keterangan :

$\mathrm{OC}_{\text {(trip) }} \quad=$ Outage Cost per Perjalanan (Rupiah)

$\operatorname{Re}$ (trip) = Pemasukan tiap perjalanan (Rupiah)

$\mathrm{EC}_{\text {(trip) }} \quad=$ Biaya listrik per perjalanan (Rupiah)
Berdasarkan perhitungan yang telah dilakukan, didapatkan tabel hasil perhitungan nilai outage cost PT. KAI Commuter Jabodetabek tahun 2015 sebagai berikut:

Tabel 4. Hasil Perhitungan Nilai Outage Cost tiap Perjalanan Operasi KRL Jabodetabek Tahun 2015

\begin{tabular}{lcc}
\hline Rute Perjalanan & $\begin{array}{l}\text { Jarak } \\
\text { (Km) }\end{array}$ & $\begin{array}{l}\text { Outage } \\
\text { Cost } \\
\text { (Rupiah) }\end{array}$ \\
\hline Bogor - Depok (PP) & 22,13 & 328.442 \\
Bogor - Depok - Manggarai & 44,924 & 1.238 .827 \\
Bogor - Depok - Manggarai - & 47,576 & 1.312 .983 \\
Jatinegara (PP) & & \\
Bogor - Depok - Manggarai - Jakarta & 54,812 & 1.797 .588 \\
Kota (PP) & 54,582 & 1.554 .330 \\
Bogor - Depok - Manggarai - Duri (PP) & 9,658 & 315.503 \\
Manggarai - Duri (PP) & 18,351 & 383.626 \\
Nambo - Depok (PP) & 32,452 & 1.225 .888 \\
Depok - Manggarai - Duri (PP) & 32,682 & 1.469 .147 \\
Depok - Manggarai - Jakarta Kota & 25,446 & 984.541 \\
(PP) & 50,803 & 1.609 .514 \\
Depok - Manggarai - Jatinegara (PP) & 11,252 & 239.335 \\
Nambo - Depok - Manggarai - Duri & 14,612 & 635.398 \\
(PP) & 9,888 & 161.370 \\
Manggarai - Tanah Abang & 22,13 & 558.761 \\
Manggarai - Kampung Bendan & 11,642 & 305.254 \\
Bojong gede - Depok & 1,364 & 76.637 \\
Manggarai - Jakarta Kota & 19,297 & 748.657 \\
Jakarta Kota - Kampung Bendan - & 21,081 & 544.739 \\
Tanjung Priok (PP) & 34,546 & 768.355 \\
Jakarta Kota - Kampung Bendan (PP) & & \\
Duri - Tangerang (PP) & 55,627 & 1.229 .640 \\
Parung Panjang - Maja (PP) & 24,278 & 536.520 \\
Tanah Abang - Serpong - Parung & 17,454 & 527.248 \\
Panjang (PP) & 27,342 & 1.086 .009 \\
\hline Tanah Abang - Serpong - Parung & \\
Panjang - Maja (PP) & & \\
Tanah Abang - Serpong (PP) & & \\
Manggarai - Bekasi (PP) & Jakarta Kota - Manggarai - Bekasi (PP) \\
\hline & & \\
& & \\
\hline
\end{tabular}

Dari tabel dan grafik-grafik diatas dapat dilihat bahwa rute perjalanan dengan nilai outage cost terbesar adalah rute Bogor - Depok - Manggarai - Jakarta Kota (PP) dengan nilai Rp 1.797.588 per perjalanannya, lalu rute perjalanan dengan nilai outage cost terendah adalah rute Jakarta Kota - Kampung Bendan (PP) dengan nilai Rp 76.637 per perjalanannya. Hal ini dikarenakan kedua rute tersebut merupakan rute yang memerlukan nilai konsumsi energi paling banyak dan sedikit pada operasi KRL Jabodetabek tahun 2015.

Hal tersebut sudah sesuai dengan logika yang ada, dimana nilai outage cost suatu perjalanan berbanding lurus dengan nilai konsumsi energi yang diperlukan karena dengan makin banyak usaha yang dibutuhkan dalam pengoperasian KRL, dalam hal ini usaha dinyatakan dalam variabel konsumsi energi KRL, maka nilai kerugian yang harus ditanggung oleh penyedia jasa KRL untuk menanggulangi usaha tersebut pun akan makin tinggi.

\section{Kesimpulan}

Nilai outage cost dari operasi KRL di Jabodetabek tidak berbanding lurus dengan panjangnya rute perjalanan yang 
ditempuh KRL, namun dengan nilai konsumsi energi yang dibutuhkan oleh KRL tiap rute perjalanannya. Hal ini ditunjukkan salah satunya pada dimana rute Bogor - Depok - Manggarai - Jakarta Kota (PP), sebagai rute yang mengkonsumsi energi listrik paling banyak dengan nilai $350,183 \mathrm{kWh}$ per perjalanannya, dimana rute ini juga memiliki nilai outage cost yang paling tinggi sebesar Rp 1.797.588 tiap pembatalan per perjalanannya. Sedangkan rute Jakarta Kota - Kampung Bendan (PP), sebagai rute yang mengkonsumsi energi listrik paling sedikit dengan nilai $14,292 \mathrm{kWh}$ per perjalanannya, dimana rute ini memiliki nilai outage cost yang paling rendah sebesar Rp 76.637 tiap pembatalan per perjalanannya.

Adanya faktor yang mempengaruhi nilai konsumsi energi yang dibutuhkan oleh KRL, yaitu banyaknya pemberhentian antar stasiun. Untuk jarak tempuh KRL yang sama, KRL dengan rute yang memiliki pemberhentian antar stasiun yang lebih banyak akan mengkonsumsi energi lebih banyak. Hal ini ditunjukkan salah satunya pada rute Bogor - Depok - Manggarai Jakarta Kota (PP) dan rute Bogor - Depok - Manggarai Duri (PP) berjarak relatif sama, yaitu +- $54 \mathrm{Km}$. Namun, kedua rute tersebut memiliki nilai konsumsi energi yang berbeda dengan rute Bogor - Depok - Manggarai - Jakarta Kota (PP) sebesar 350,183 kWh dan rute Bogor - Depok Manggarai - Duri (PP) sebesar 302,795 kWh. Hal ini dikarenakan rute Bogor - Depok - Manggarai - Jakarta Kota (PP) memiliki pemberhentian antar stasiun lebih banyak yaitu 24 kali dibandingkan rute Bogor - Depok Manggarai - Duri (PP) yang memiliki pemberhentian antar stasiun sebanyak 20 kali.

\section{Referensi}

[1] PT Kereta Api Indonesia (Persero), Laporan Tahunan 2015. Bandung: PT Kereta Api Indonesia, 2016.

[2] Turan Gonen. Electric Power Distribution System Engineering. California: CRC Press. 2007.

[3] Hachimenum N. Amadi, Ephraim N. C. Okafor. Analysis of Methodologies for the Evaluation of Power Outage Costs. International Journal of Engineering Research and Technology. 2015; 4(5): 956.

[4] Sinan Küfeog lu, Economic Impacts of Electric Power Outages and Evaluation of Customer Interruption Costs. Doctoral Dissertation. Finlandia: Aalto University, 2015.

[5] E.E. Leamer, Macroeconomic Patterns and Stories. United States: Springer, 2009.

[6] Kementrian Energi dan Sumber Daya Mineral. 31-2014. Peraturan Menteri Energi dan Sumber Daya Mineral Republik Indonesia Nomor 31 Tahun 2014 tentang Tarif Tenaga Listrik yang Disediakan oleh Perusahaan Perseroan (Persero). Jakarta: PT Perusahaan Listrik Negara, 2014.

[7] H.Partab. Modern Electric Traction. Delhi: Pritam Surat \& Brothers. 1973

[8] J. R. Billinton, Methods to Consider Customer Interruption Costs in Power Systems Analysis. CIGRE Task Force. 2001. 